\section{Intramolecular Optical Metal to Ligand Charge Transfer between Remote Redox Centers}

\section{ARND VOGLER* and HORST KUNKELY}

Institut für Anorganische Chemie, Universität Regensburg, Universitätsstrasse 31, D.8400 Regensburg, F.R.G.

(Received February 11, 1988)

Long-range electron transfer involving transition metal complexes has been investigated extensively during recent years [1]. In this context it is of interest if intramolecular electron transfer between remote redox centers can occur also by direct optical excitation. This process requires the occurrence of charge transfer (CT) absorptions which belong to electronic transitions from the electron donor to a distant acceptor. The CT interaction between donor and acceptor may be facilitated by throughbond interaction even if donor and acceptor are separated by more than one bond. While systematic studies of organic systems were carried out quite recently $[2,3]$ much less is known about CT interaction between remote redox centers of inorganic molecules.

The majority of intramolecular optical CT transitions of metal complexes involves donors and acceptors which are directly connected by chemical bonds [4]. These are metal to ligand CT (MLCT) and ligand to metal CT (LMCT) transitions [4]. In addition, optical CT transitions between redox centers are known which are separated by one intervening metal or ligand. Binuclear complexes of the type $\mathrm{M}_{\mathrm{red}}-\mathrm{L}-\mathrm{M}_{\mathrm{ox}}$ with a bridging ligand $\mathrm{L}$ are characterized by metal to metal CT (MMCT) absorptions [4] while the electronic spectrum of mononuclear complexes $L_{\text {red }}-M-L_{o x}$ which contain a reducing and an oxidizing ligand display ligand to ligand $\mathrm{CT}$ (LLCT) bands [5].

There seem to be only two reports on intramolecular optical CT between redox centers which are separated by more than one ligand or metal. A MMCT band was identified in the absorption spectrum of a trinuclear complex of the type $\mathrm{M}_{\mathrm{red}}-$ $\mathrm{L}-\mathrm{M}-\mathrm{L}-\mathrm{M}_{\mathrm{ox}}$ [6]. For a complex of the general composition $\mathrm{M}_{\mathrm{red}}-\mathrm{L}-\mathrm{M}-\mathrm{L}_{\mathrm{ox}}$ evidence for the appearance of a MLCT band was obtained [7]. In this case donor and acceptor are separated by a ligand and a metal.

The present study adds further evidence to the occurrence of long-range optical CT transitions in metal complexes. It is anticipated that optical CT

\footnotetext{
*Author to whom correspondence should be addressed.
}

involving even more distant redox centers will be discovered in the future.

The trinuclear complexes [(bipy) $\left(\mathrm{H}_{2} \mathrm{O}\right) \mathrm{Pt}^{\mathrm{II}}-\mathrm{NC}-$ $\mathrm{M}^{\mathrm{I}}(\mathrm{CN})_{4}-\mathrm{CN}-\mathrm{Pt}^{\mathrm{I}}($ bipy $\left.)\left(\mathrm{H}_{2} \mathrm{O}\right)\right]$ with bipy $=2,2$ bipyridyl and $\mathrm{M}=\mathrm{Fe}, \mathrm{Ru}$ and $\mathrm{Os}$ were prepared by the reaction of aqueous solutions of [Pt(bipy $\left.)_{2}\right]$ $\left(\mathrm{ClO}_{4}\right)_{2}$ [8] with $\mathrm{K}_{4}\left[\mathrm{M}(\mathrm{CN})_{6}\right]$ [9] according to the stoichiometry

$$
\begin{aligned}
& 2\left[\mathrm{Pt}(\text { bipy })_{2}\right]^{2+}+\left[\mathrm{M}(\mathrm{CN})_{6}\right]^{4-}+(n+2) \mathrm{H}_{2} \mathrm{O} \longrightarrow \\
&\left\{\left[(\text { bipy })\left(\mathrm{H}_{2} \mathrm{O}\right) \mathrm{PtNC}\right]_{2} \mathrm{M}(\mathrm{CN})_{4}\right\} n \mathrm{H}_{2} \mathrm{O}+2 \text { bipy }
\end{aligned}
$$

This substitution reaction is certainly facilitated by the kinetic lability of one bipy ligand in the complex cation $\left[\mathrm{Pt}(\mathrm{bipy})_{2}\right]^{2+}[8]$. The neutral trinuclear complexes precipitated as insoluble substances which were washed with hot water, ethanol, acetone and ether and obtained as analytically pure powders. The red-brown iron complex crystallized with four molecules of water $(n=4)$. For the orange $\mathrm{Ru}$ complex $n$ was 8 . The orange Os complex did not contain crystal water $(n=0)$.

The formation of cyanide bridges in the trinuclear complexes was confirmed by the IR spectra in the region of the stretching vibrations of the cyanide ligands. The spectra display lower-frequency bands below $2100 \mathrm{~cm}^{-1}$ which are indicative of terminal cyanides and higher-frequency absorptions above $2100 \mathrm{~cm}^{-1}$ which are consistent with the presence of cyanide bridges $[10-12]$. They appear at 2085 and $2120 \mathrm{~cm}^{-1}$ for $\mathrm{M}=\mathrm{Fe}$, at 2090 and $2140 \mathrm{~cm}^{-1}$ for Ru and at 2088 and $2136 \mathrm{~cm}^{-1}$ for Os.

The electronic absorption spectra of the trinuclear complexes could not he measured in solution since these compounds are completely insoluble in all solvents. Spectra were obtained by scattered transmission spectroscopy of aqueous suspensions of the solid samples and recorded in absorbance versus wavelength. The spectrum of the trinuclear complexes are dominated by intense long-wavelength absorptions at $\lambda_{\max }=475 \mathrm{~nm}$ for $\mathrm{M}=\mathrm{Fe}$ (Fig. 1), $410 \mathrm{~nm}(\mathrm{Ru})$ and $428 \mathrm{~nm}(\mathrm{Os})$. The intensity of these bands is estimated to be approximately $\epsilon \sim$ $10^{4}$ at the absorption maximum. This estimation is based on the comparison with the intraligand $\pi \pi^{*}$ absorptions which appear at 325 and $339 \mathrm{~nm}$ (Fig. 1). Other bipy complexes of Pt(II) are also characterized by these intraligand $\pi \pi^{*}$ bands [13]. The intense long-wavelength absorptions of the trinuclear complexes [(bipy) $\left(\mathrm{H}_{2} \mathrm{O}\right) \mathrm{Pt}^{\mathrm{H}_{-}}-\mathrm{CN}-\mathrm{M}^{\mathrm{II}}(\mathrm{CN})_{4}-\mathrm{CN}-$ $\mathrm{Pt}^{\mathrm{II}}$ (bipy) $\left(\mathrm{H}_{2} \mathrm{O}\right)$ ] are assigned to the MLCT transitions from M(II) to the bipy ligands which are coordinated to $\mathrm{Pt}(\mathrm{II})$. This assignment is based on the following considerations. The MLCT band moves to higher energies from $\mathrm{M}=\mathrm{Fe}$ to $\mathrm{Os}$ and $\mathrm{Ru}$ since $\mathrm{M}$ (II) becomes increasingly reducing in this series: 


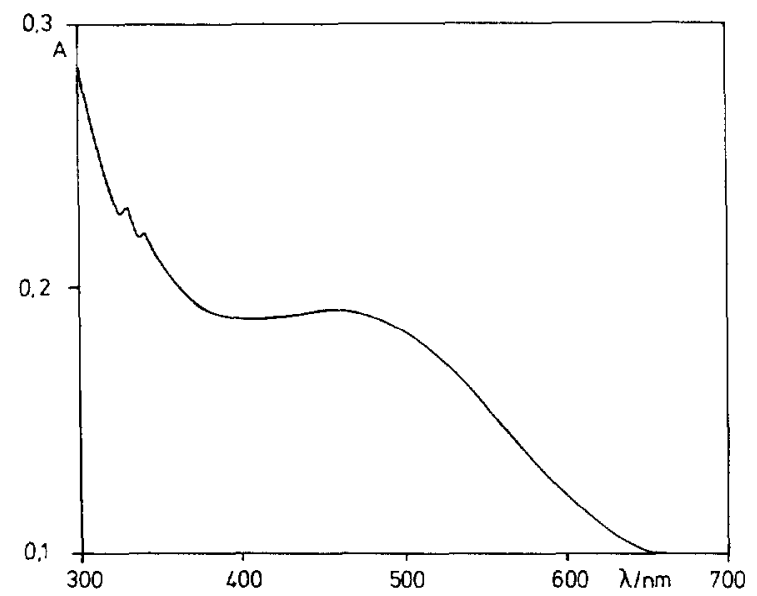

Fig. 1. Absorption spectrum of $\left[(\right.$ bipy $)\left(\mathrm{H}_{2} \mathrm{O}\right) \mathrm{Pt}-\mathrm{NC}-$ $\mathrm{Fe}(\mathrm{CN})_{4}-\mathrm{CN}-\mathrm{Pt}\left(\mathrm{H}_{2} \mathrm{O}\right)$ (bipy)] at room temperature; absorbance in arbitrary units.

$E_{1 / 2}=0.19 \mathrm{~V}$ versus $\mathrm{SCE}\left(\mathrm{Fe}(\mathrm{CN})_{6}^{4-}\right), 0.40 \mathrm{~V}$ $\left(\mathrm{Os}(\mathrm{CN})_{6}{ }^{4-}\right)$, and $0.70 \mathrm{~V}\left(\mathrm{Ru}(\mathrm{CN})_{6}{ }^{4-}\right)$ [14]. The mononuclear components of the trinuclear complexes do not absorb strongly in the region of the M(II) to bipy LMCT bands. The hexacyano anions $\left[\mathrm{M}(\mathrm{CN})_{6}\right]^{4-}$ absorb only below $300 \mathrm{~nm}$ [9]. The other mononuclear component [Pt(bipy) $\left(\mathrm{H}_{2} \mathrm{O}\right)$ $(\mathrm{NC})]^{+}$is not known. However, the spectra of [Pt$\left.(\text { bipy })_{2}\right]^{2+}$ and $\left[\mathrm{Pt}(\text { bipy)en }]^{2+}\right.$ with en = ethylenediamine may be taken for comparison. These complexes do not show any intense absorptions above $380 \mathrm{~nm} \mathrm{[13].}$

In conclusion it has been shown that the electronic spectra of the trinuclear complexes [(bipy) $\left(\mathrm{H}_{2} \mathrm{O}\right)$ $\mathrm{Pt}^{\mathrm{II}}-\mathrm{NC}-\mathrm{M}(\mathrm{CN})_{4}-\mathrm{CN}-\mathrm{Pt}{ }^{\mathrm{II}}\left(\mathrm{H}_{2} \mathrm{O}\right)($ bipy $\left.)\right]$ are characterized by an intense MLCT band which involves an electronic transition from the reducing $M($ II) to the bipy ligand. This CT between remote redox sites may be facilitated by through-bond interaction via the intervening bridging cyanide and the Pt(II) metal center.

\section{Acknowledgements}

Financial support for this research by the Deutsche Forschungsgemeinschaft and the Fonds der Chemischen Industrie is gratefully acknowledged.

\section{References}

1 (a) C. M. Lieber, J. L. Karas and H. B. Gray, J. Am. Chem. Soc., 109, 3778 (1987); (b) D. Heiler, G. McLendon and P. Rogalaskyi, J. Am. Chem. Soc., 109, 604 (1987); (c) N. Liang, C. H. Kang, P. S. Ho, E. Margoliash and B. M. Hoffman, J. Am. Chem. Soc., 108, 4665 (1986).

2 H. Oevering, M. N. Paddon-Row, M. Heppener, A. M. Oliver, E. Cotsaris, J. W. Verhoeven and N. S. Hush, J. Am. Chem. Soc., 109, 3258 (1987).

3 K. W. Penfield, J. R. Miller, M. N. Paddon-Row, E. Cotsaris, A. M. Oliver and N. S. Hush, J. Am. Chem. Soc., 109, 5061 (1987).

4 A. B. P. Lever, 'Inorganic Electronic Spectroscopy', Elsevier, Amsterdam, 1984.

5 A. Vogler and H. Kunkely, J. Chem. Soc., Chem. Commun., 1616 (1986).

6 A. von Kameke, G. M. Tom and H. Taube, Inorg. Chem., 17, 1790 (1978).

7 C. A. Bignozzi, S. Roffia and F. Scandola, J. Am. Chem. Soc., 107, 1644 (1985).

8 S. E. Livingstone and B. Wheelahan, Aust. J. Chem., 17, 219 (1964).

9 A. Vogler, A. H. Osman and H. Kunkely, Inorg. Chem., 26, 2337 (1987).

10 D. A. Dows, A. Haim and W. K. Wilmarth, J. Inorg. Nucl. Chem., 21, 33 (1966).

11 A. Vogler and H. Kunkely, Ber. Bunsenges. Physik. Chem., 79, 301 (1975).

12 J. Ribas and A. Escuer, Transition Met. Chem., 10, 466 (1985), and refs. therein.

13 D. L. Webb and L. A. Rossiello, Inorg. Chem., 10, 2213 (1971).

14 J. C. Curtis and T. J. Meyer, Inorg. Chem., 2l, 1562 (1982). 